\title{
El Salvador 1984-1988: guerra civil, economía y política
}

\author{
Raúl Benitez Manaut*
}

En el presente ensayo esbozaremos algunas hipótesis sobre la realidad contemporanea salvadorefia, a partir de tres variables: la guerra civil, la economia y la política.

Si bien/el drama que vive el pueblo salvadorefo tiene una multitud de orlgenes, que han confluido durante los ochenla en la guerra civil, entre los factores históricos más importantes que se articulan para otorgarle a la crisis la dimensión actual, pueden destacarse:

1) La ausencia de mecanismos de negociación política en el seno del Estado, dado que éste nunca modificó de manera radical el orden liberaloligárquico consolidado en los úllimos treinta anos del siglo XIX. Esto hace que en el pais la política se delermine por un juego de alianzas entre la élite, formada principalmenle por la llamada "oligarquia cafetalera", donde la economía, a pesar del luerte impulso modernizador vivido entre 1950 y 1978, no evoluciona hacia un régimen más equitativo de distribución del ingreso.1 Por ello, en momentos de agudo entrentamiento, la política se manifiesta como guerra. Esta es una de las razones por las cuales el movimiento revolucionario resalla el carácler excluyente del Eslado y recuerda con gran énlasis la matanza de enero de 1932, donde fueron asesinados más de 30 mil campesinos del occidente del pais por las fuerzas gubernamentales. ${ }^{2}$

2) En la década de los setenta se agudiza la crisis política por múltiples acontecimientos: la guerra de julio de 1969 con Honduras, aunque representó un triunfo militar del ejércilo salvadoreno, obligó a repatriar a

- Investigador del Centro de Investigaciones Interdisciplinarias en Humanidades, UNAM, México. 
una gran masa de campesinos, que rápidamente se asentaron en la periferia de las ciudades, y en el campo comienzan a intensificarse las demandas por la relorma agraria. Este elemento se convitió en allamente explosivo por la gran densidad demográfica del país: 229 habitantes por $\mathrm{Km}$. cuadrado en $1980 .^{3}$

3) En los afios setenta surgen y se desarrollan en un contexto favorable las organizaciones armadas revolucionarias y gran cantidad de organizaciones populares. El contexio de gran polaridad política hace que para el Estado se genere una situación de ingobernabilidad y que emerga la opción revolucionaria como posible hacia 1978 y 1979.

4) El golpe de Estado del 15 de octubre de 1979, dirigido por la oficialidad joven del ejército, fue la última oportunidad para que se lograra una salida negociada al conflicto sociopolítico. El fracaso del proyecto reformista y la recuperación del poder político por las fuerzas más retardatarias duranle 1980,4 provocan que durante este ano se den las condiciones para el estallido de la guerra civil.

5) En 1980 se produce la polarización total del pais. Se genera una situación de doble poder: el gobierno, apoyado de manera tolal por Estados Unidos, y las fuerzas democráticas y revolucionarias, que viven un acelerado proceso de convergencia política con la creación del Frente Democrálico Revolucionario (FDA) en abril y el Frente Farabundo Marti para la Liberación Nacional (FMLN) en octubre.

Al polarizarse la siluación, los faclores militares de la crisis son los que pasan a definir el devenir de los acontecimientos. Desde 1980 la guerra sustituye a la politica como eje del conflicto social. En enero de 1981 estalla la guerra civil abierta, cuando el Comando Central del FMLN anuncia la "Otensiva General Militar" contra el régimen. Las transformaciones sufridas por el conjunto de la esinuctura social salvadorena son muy profundas a consecuencia de esta guerra. La economía se transforma rápidamente en una "economia de guerra" y "para la guerra". La polflica adquiere olro carácter: por un lado, en el polo gubernamental, se busca la instilucionalización de un nuevo régimen político excluyenle de las fuerzas populares, que a su vez arlicule un consenso necesario; y en el polo revolucionario se concibe a la política de dos formas intimamente articuladas: la lucha por consolidar su hegemonia en el conjunto de los sectores sociales del pals, principalmente los populares, y la lucha intemacional para lograr su reconocimiento y el aislamiento del régimen.

De 1981 a 1984 se generaliza la guerra civil. El FMLN consolida sus posiciones en aproximadamente una tercera parte del pais (el territorio salvadorefio tiene casi 22 mil $\mathrm{Kms}$. cuadrados, por lo que el territorio de influencia insurgënle es de siele mil), principalmenle en el norte y oriente: los departamenlos de Morazán, Chalalenango, parte de La Unión,

528. 
Cabañas, San Miguel y Usulután y en el cerro Guazapa. Desde 1981 los prolagonistas de dicha guerra son tres: las fuerzas gubernamentales, los Estados Unidos y la alianza FDR-FMLN; las fuerzas armadas de EI Salvador y Estados Unidos aclúan tusionadas en el esfuerzo militar contra la insurgencia. La intervención norleamericana, justificada por motivos de seguridad nacional, mediante el razonamiento de que no puede repetirse olra situación como la nicaragüense, se basa en la dirección estratégica de la guerra a través del U.S. Milltary Group y su tolal financiamiento. El U.S. Milltary Group dirigie el conjunto de las acciones de las fuerzas armadas de El Salvador, a la vez que les provee de todo el equipo bélico necesario y entrena a sus efectivos, a través de los diversos programas de asesoria y asistencia. ${ }^{5}$

A nivel político se busca que nuevas fuerzas, que anteriormente eran incluso consideradas como una "amenaza" para el poder oligárquico, como el Partido Demócrata Cristiano (PDC), logren restaurar el sistema político. Para ello se impulsa un proyecto reformista contrainsurgente, cuyas partes medulares son disefhadas por el gobienro de Eslados Unidos -es el caso de la redelinición de la relorma agraria, cuyos proyeclos son financiados por la Agencia para el Desarrollo Internacional del gobierno estadunidense (AID). En esta restauración política so intenta legitimar al régimen a Iravés de una Asamblea Cosnlituyente, elegida en marzo de 1982, que redacta una nueva constitución que entra en vigor en diciembre de $1983,{ }^{6}$ e inaugura un nuevo gobierno constitucional, surgido de las elecciones presidenciales de marzo de 1984, donde se elige a José Napoleón Duarte como presidente, por un período de cinco anos. A su vez, es lotalmente redefinido el rol de los partidos políticos en el país. Los sectores más cercanos a la oligarqula le quitan su apoyo al Partido de Conciliación Nacional (PCN), y fundan en septiembre de 1981 el Partido Alianza Republicana Nacionalista (ARENA). ${ }^{7}$ La lucha política legal. en este contexto contrainsurgente, se circunscribe a los partidos políticos ubicados del centro a la extrema derecha, y la disputa por el poder se da principalmente enlre el PDC y ARENA, El gobierno demócrata cristiano, a partir de 1984, no logra conquistar de manera total el apoyo del alto mando de las fuerzas armadas y de la oligarqula, por lo que se sostiene principalmente con el respaldo norteamericano.

\section{1) La economia de guerra}

Uno de los rasgos más nolorios de la crisis económica que vive EI Salvador es el descenso acelerado de la actividad económica, expresado en los niveles del Producto Interno Brulo (PIB): entre 1970 y 1975 creció a una lasa promedio anual de $5.5 \%$; entre 1975 y 1980 , al $1 \%$; en 1980 fue de $-8.7 \%$; en 1981 , de $-8.6 \%$; en 1982 , de - $5.3 \%$; en 1983 , de - 
$0.7 \%$; en 1984 , de $1.5 \%$; y en 1985 fue de $1.6 \%$, según la CEPAL. ${ }^{8}$ A consecuencia de eslo, son múltiples los indicadores que comprueban el descenso de la calidad de la vida. Por ejemplo, comparando 1985 con 1977, se ha incrementado la incidencia de la "pobreza extrema": en 1977. de un tolal de casi 800 mil familias, 254 mil se encontraban en esa siluación; mientras que en 1985, de 946 mil farnilias, 418 mil $(50 \%$ de la población) se encuentran en esas condiciones. ${ }^{9}$ Las cifras de anallabelismo, consideradas entre las más altas de América Latina, eran en 1975 del $38 \%$ de la población en edad de leer y escribir, y en 1985 de $32 \% .{ }^{10}$ En el rubro de la salud, el número de camas de hospital por cada mil habilantes desciende de 2.1 en 1970 a 1.2 en 1982.11 y la mortalidad infantil es la más alta de América Central, siendo en 1986 de 91 muerles por cada mil nifios entre 0 y 5 años. ${ }^{12}$

Una de las consecuencias de la economia de guerra en el pals, es la distorsión de la actividad económica. Por el cierre de empresas (el ritmo de inversión de capital privado es de un promedio anual de $10.1 \%$ entre 1970 y 1975 ; de $7.2 \%$ entre 1975 y 1979 ; de $-28.2 \%$ en 1980 ; de $-10.8 \%$ en 1981 ; de $10.1 \%$ en 1982 y de $-9.1 \%$ en 1983$),{ }^{13}$ el mercado se transforma en dirección hacia la economia informal: el desempleo abierto crece de $10.2 \%$ de la poblacion económicamente activa (PEA) en 1970, a $30 \%$ en 1984 , mientras que el subempleo crece de $44.6 \%$ de la PEA en 1970 al $55 \%$ en 1980.14

La principal razón que explica este descenso en la calidad de la vida, se debe al privilegio de las necesidades bélicas. En síntesis, esto se expresa por el incremento del gasto militar en detrimento de los gastos sociales del Estado: en 1979 el gaslo mililar consumia el $8.7 \%$ del gasto gubernamental, mientras que en 1986 éste es de $28.3 \%$. En cambio, el gasto en educación disminuye del $20.1 \%$ al $15.29 \%$ en el mismo período. y el gasto en salud baja del $10.17 \%$ al $7.10 \% .^{15}$

Entre las más notables modificaciones estructurales de la economia salvadorefia, se encuentran la participación económica de los salvadorefios residenles en Eslados Unidos, y la incidencia directa de la asistencia económica y militar de Estados Unidos en la balanza de pagos. Estos dos factores, producto direclo de la guerra civil, eran prácticamente inexistentes al inicio del conílicto, y en la actualidad son el pilar de la economia y el gobierno. Sin ellos muy probablemente la economla habría sucumbido.

\section{2) Refuglados Internos y externos}

Las cifras sobre la canlidad de salvadoreños desplazados de sus lugares de habitación por efecto directo de la guerra (por vivir en zonas

de combate o indirecto (por desplazamiento torzoso o por la necesidad 
de encontrar medios de vida alternativos) difieren. No obstante, las estimaciones globales senalan que alrededor de un millón de personas $\mathbf{s e}$ encuentran en dichas condiciones: medio millón en el interior de El Salvador, desplazadas del norle y oriente del pais hacia el occidente y las principales ciudades, y medio millón fuera del pais, principalmente en Eslados Unidos, y, en menor medida, Canadá, México, Guatemala, Honduras, Costa Aica, Nicaragua y Panamá. En su mayor parte esta población es campesina, que huye o es forzada a emigrar. Esta población es la que ha aumentado notablemente el sector inlormal de la economia y el desempleo y subempleo.

Cifras oficiales, elaboradas por el gobiemo de El Salvador senalan que las primeras migraciones causadas por la crisis política del país se dieron en 1980 en el poblado de Las Vueltas, Chalatenango, cuando se desplazó a 2 mil personas. El saldo de personas que legalmente han abandonado el país y no han relornado, entre 1982 y 1986 es de 280 mil $790,{ }^{16}$ mientras que los desplazamientos internos, realizados por el gobiemo, principalmente para aislar a la insurgencia de la población campesina, se estiman en alrededor de 400 mil (bajo la lilosotia contrainsurgente que busca aislar "al pez del agua"). ${ }^{17}$ Los departamentos donde ha sido más numeroso el desplazamiento de población coincide con los lugares donde la presencia del FMLN es fuerte: Morazán, 69 mil; Usululán 48 mil; San Miguel, 43 mil; San Vicenle, 38 mil; y Chalalenango, 30 mil. ${ }^{18}$

Otras luenles de información mencionan que los salvadorenos en México (que en su mayoria Iratan de cruzar la frontera norle hacia Eslados Unidos) son en promedio 120 mil, y que en Guatemala radican 70 mil; en Nicaragua 17 mil 500 ; en Honduras 19 mil; en Cosla Rica 10 mil y en Panamá y Belice 3 mil. ${ }^{19}$ Mientras que en Estados Unidos la cilra supera el medio millón, según cifras del gobierno de ese país, de los cuales solo 34 mil serian residentes legales. ${ }^{20}$ Una invesligación, que realizó su estudio con base en información local, proveniente de los principales centros urbanos receptores de inmigrantes ilegales de Estados Unidos, menciona que para 1987 habría un mínimo de 543 mil y un máximo de 903 mil salvadoreños. ${ }^{21}$

\section{3) La Intervenclón milltar norteamericana.22}

Cuando Estados Unidos, en la posguerra, forlalece sus lazos mililares en América Lalina como una medida para confirmar su hegemonia, no consideró estratégico a EI Salvador. Por ello, los niveles de asistencia económica y militar nunca fueron superiores a los "normales" (en términos comparativos). A fines de la década de los setenta, se revalora el papel estralégico y geopolítico de la Cuenca del Caribe por dos aconlecimientos: la firma de los Tralados Carter-Torrijos con el gobierno panameño en 1977, y la crisis del somocismo y el ascenso del sandi- 
nismo en Nicaragua en 1979. La grave crisis política que vivía EI Salvador fue vista, repentinamente, como una polencial amenaza a la seguridad estadunidense si el movimiento insurgente lograba acceder al poder. El espectro de la generalización de los movimientos revolucionarios en la región - con base en la teoría del dominó-23, al cuestionar su hegemonia prelende ser neutralizado. La estralegia de "contención" adoptada se implementó rápidamenle.

Primero, si bien algunos sectores vieron con simpalia al gobierno reformista (que gobernó El Salvador enlre el 15 de oclubre de 1979 y el 9 de enero de 1980), la idea de relorzar a las luerzas armadas, adaplar las reformas a la contrainsurgencia y buscar fuerzas polílicas capaces de restaurar el sistema polílico, fue lo que predominó en el diseño contrainsurgente implementado. Esto se logra apoyando el pacto entre el PDC y la Fuerza Armada, firmado el 9 de enero de 1980.24 Inmediatamente después, en febrero, se contorma el U.S. Milltary Group, que pasa a dirigir estratégicamente la guerra. ${ }^{25}$

Segundo, para evitar el derrumbe del gobierno, se inicia un ambicioso programa de asistencia que crecientemente sustituye al Estado salvadorefio en sus funciones de planilicación y dirección de la economía y el pais. Entre 1981 y 1987, la asislencia olicial a El Salvador es de aproximadamente 3 mil millones de dólares. ${ }^{26}$ En promedio, se han dedicado anualmente más de $\mathbf{4 0 0}$ millones de dólares. Tomando en cuenta el PIB del país (que, por ejemplo, en 1984 lue de aproximadamente mil 800 millones de dólares) ${ }^{27}$ y el gasio gubernamental, la ayuda de Estados Unidos es del $20 \%$ para el primero - en promedio-; y para el segundo, ya en 1986, la asistencia de Estados Unidos supera el gasto gubernamental (en 1986 éste fue de 582 millones de dólares, y la asistencia de Estados Unidos para el año fiscal 1987 fue de 608 millones de dólares). ${ }^{2 \theta}$ Además, a lo anterior hay que agregar la contribución al PIB que realizan los salvadorenos residentes en Estados Unidos (recursos popularmente conocidos como "pobredólares"), que para 1986 y 1987 se acerca a un mil millones de dólares. Eslo significa que, a nivel cuanlitalivo ,la guerra ha hecho que el PIB del pais se genere mayoritariamente en el exlerior, (siluación notablemente sul generls en América Latina, pues El Salvador, a diterecia de la mayoria de paises, por la "economia de guerra" es un país importador de capilales).

La asistencia de Estados Unidos se dedica en un $70 \%$ al esfuerzo bélico y sólo un $30 \%$ se destina al benelicio de la población. ${ }^{29}$ La asistencia militar, a su vez, se reparte entre el esfuerzo de entrenamiento a los miembros de las fuerzas armadas, la dotación de equipo militar y las necesidades auxiliares de la guerra, como reconstrucción de caminos y puentes —para facilitar el tránsito de tropas. 
Para evitar el derrumbe del ejército, Estados Unidos ha propiciado su reestrucluración tolal, lavoreciendo su prolesionalización. En 1979 sus efectivos eran de 15 mil, incluidos los cuerpos de seguridad; en 1987 suman 56 mil. Asimismo, se ha fortalecido notablemente a la fuerza aérea, por la importancia que tiene para la conlriansurgencia. Entre las modificaciones sustanciales, producto de la estrategia norteamericana, se encuentran, a nivel organizalivo y técnico, comparando 1979 con 1987: de 13 batallones de maniobra a 41 ; de 28 aviones de combale a 63; de 5 helicópleros a 72 y de 4 barcos de guerra a 33.30

De 1981 a 1988, en El Salvador se han aplicado dos estralegias de contrainsurgencia. La primera, ensayada entre enero de 1981 y 1984, se basaba en la idea de que al FMLN se le podía contener y combatir con resultados positivos mediante el llamado "cerco y aniquilamiento". Esta estrategia, implementada ulilizando como plantemaiento doctrinario la idea de "Rápido Despliegue", que el ejército de Estados Unidos elabora a fines de los selenta para no repetir los errores cometidos en Vielnam, atribuidos principalmente al "gradualismo" y a la presencia directa de tropas busca, a través del empleo de grandes contingentes militares -para tener una superioridad táctica de fuerzas-, en un plazo corto de liempo, aniquilar las concentraciones insurgenles más importantes. Entre 1981 y 1983 , en diversas campanas militares, como las desarrolladas en Chalatenango del 30 de septiembre al 10 de octubre de 1981; en Morazán entre el 7 y el 29 de diciembre del mismo año; en San Vicente durante mayo y junio de 1983 (operación conocida como "Bienestar para San Vicente") y contra el cerro Guazapa en varias ocasiones, no se alcanzan los objetivos militares propuestos. Por el contrario las ofensivas gubernamentales jamás llegan a la lase linal (el aniquilamiento) y la insurgencia se forlalece tácticamente. Según el departamento de Estado de Eslados Unidos, el FMLN de tener 2 mil guerrilleros en 1980 pasa a un mínimo de 9 mil y un máximo de 12 mil en 1984. ${ }^{31}$

Para frenar lo anterior, se busca una allernativa con la cual las fuerzas armadas superen el equifibrio militar y para que el FMLN no tenga la posibilidad de romperlo a su favor. Para ello se cambia la estrategia, implementando las recomendaciones de la doctrina de guerra de baja Inlensldad, 32 olorgado a la contrainsurgencia una dimensión integral ya no sólo militar.

En lo militar, se cuestiona la estrategia de "Rápido Despliegue", considerando ahora que la guerra debe realizarse mediante pequefios destacamentos capaces de penetrar en el territorio bajo control del FMLN. Para ello se crean los batallones "cazadores", más rápidos y menos numerosos, y se fortalecen las pequenas unidades llamadas "Patrullas de Reconocimienlo de Alance Largo" (PRAL). También se busca crear una base social de apoyo (los comilés de Defensa Civil) y se forlalece a 
la fuerza aérea y la aerotransportación de las Iropas. Por olro lado se entaliza el carácter político de la guerra, para lo cual es creado en 1985 el Ministerio de Cultura y Comunicaciones, a fin de poder llevar adelante "la guerra psicológica", y en 1986 se implementa el "Plan Unidos para Reconstruir" (UPR), cuyos planteamientos se basan en que la guerra es $90 \%$ política y sólo el $10 \%$ es militar. ${ }^{33}$ A pesar de lo anterior, no se logra ninguna de las tres premisas de la estrategia de Estados Unidos: la reactivación de la economía, la consolidacion del régimen y la ruptura del equilibrio militar a favor de las fuerzas armadas. Por el contrario, en los tres aspeclos mencionados, la siluación se agrava en detrimento de la estrategia de Estados Unidos y el gobierno.

\section{4) La guerra y la estralegla revoluclonarla}

En el campo revolucionario, dada la diversidad de organizaciones que integran el FMLN ${ }^{34}$, desde 1978 son puestas en práctica diversas eslrategias y tácticas que en algunos momentos incluso son antagónicas. Fundamentalmente predominan dos posiciones. La primera, motivada por el triunlo sandinista en Nicaragua, busca inlegrar la participación activa del coniunto de la población a la olensiva militar guerrillera (estrategia "insurreccional"). La segunda hace énfasis en que se debe dar un proceso de acumulación de luerzas, principalmente en las zonas más deprimidas del país (estrategia de "guerra popular prolongada"). Al crearse el FMLN no hay una delinición en favor de alguna de las dos posiciones, hecho que en ocasiones repercute en la lalta de coordinación de las acciones militares insurgentes. Esta contradicción aflora hacia 1983, y, a partir de esla fecha, se produce una fusión que combina ambas estrategias, buscando el fortalecimiento del ejército insurgente y sefialando que la participación activa de la población debe buscarse cuando se rompa el equilibrio militar en favor del FMLN, en el momento en que las acciones guerrilleras urbanas adquieran importancia.

La consolidación del FMLN es manitiesla en varios indicadores. Entre los más significativos se encuentra el hecho de que ninguna de las campanas militares contrainsurgentes ha sido exitosa. Además, en sus ofensivas, el FMLN ha demostrado creciente capacidad para asestar golpes de gran importancia al gobierno.Otro indicador es que, a partir de que se implementa la guerra de baja intensidad por la fuerzas armada, ésta no sólo no ha logrado éxito contra el FMLN, sino que, para contrarrestar dicha estrategia, éste ha extendido su acción hacia el occidente del pais y las zonas urbanas. Igualmente se ha reactivado la lucha reinvindicativa de los sectores populares en las ciudades.

Los balances militares elaborados por ambas fuerzas no coinciden en las cifras, sin embargo, es evidente en las esladisticas existentes el 
gran aumento de las acciones en los años que lleva el conlliclo. De una población eslimada de cinco a seis millones de habitantes (el último censo se realizó en 1971), han muerlo víctimas de la violencia política 60 mil personas no consideradas combatientes de alguno de los dos ejércitos. Desde el estallido de la guerra en enero de 1981, los balances de los combales son los siguientes: en 1981, el FMLN afirma que causó 5 mil 133 bajas al ejército. Para 1982 y 1983, estadísticas de la Universidad Centroamericana sefialan que el ejércilo luvo 3 mil 979 muertos y 2 mil 934 heridos. El Ministerio de Defensa de El Salvador sosliene que sus bajas entre julio de 1982 y mayo de 1984 son de 3 mil 347 muertos, 5 mil 978 heridos y 598 desaparecidos. ${ }^{35}$ La Universidad Centroamericana reporta que, según la fuerza armada, ésta causó al FMLN, en 1985, mil 948 bajas y en 1986 mil 677 . Mientras que el FMLN afirma que causó al ejército 6 mil 084 bajas en 1985 y 6 mil 151 en $1986 .{ }^{36}$ El balance para 1987 es el siguiente: según el FMLN, provocó a la fuerza armada 8 mil bajas. El jefe del Estado Mayor de las fuerzas armadas, sefialó que el FMLN luvo un lotal de dos mil 586 bajas y que el ejército sufrió tres mil 285 bajas, entre muertos y heridos. ${ }^{37}$

Las estadísticas anteriores muestran el incremenlo cuantitalivo de los enfrentamientos militares de 1981 a 1987. A nivel cualitalivo, es preciso hacer las siguientes consideraciones: 1) ambos ejércitos han aumentado nolablemenle su capacidad de alaque; 2 ) no ha sido rolo a favor de ninguno el equilibrio militar, observándose principalmente a consolidación del FMLN en las áreas bajo su control, donde incluso es evidente la existencia de un poder popular en funciones (control económico, político y militar); 3) la fuerza armada ha logrado impedir en términos generales que el FMLN pueda actuar en los principales centros urbanos; 4) el FMLN ha logrado dificultar el acceso por tierra de la fuerza armada hacia las zonas bajo su control (en los úllimos tres affos son superiores las bajas de la fuerza armada causadas por minas, que en combate), por ello, la tendencia es al forlalecimiento de la aviación, para contrarrestar esta deficiencia láctica del ejércilo.

\section{5) La reconstrucclón del sistema politico}

El primer indicador de que la situación política de El Salvador es sumamente grave se da en 1979. El 15 de oclubre de ese ano el ejército practicamente se divide en dos, cuando la llamada "juventud militar" da un golpe de Estado apoyada por los sectores progresistas del país. El sistema politico, encabezado por el $\mathrm{PCN}$, que en las dos últimas elecciones presidenciales de 1972 1977 había liegado al poder mediante grandes fraudes electorales, se derrumba por completo. El pais se encuentra en una grave "crisis orgánica", siendo evidentes en ese momento Ires proyectos pollticos: el conservador, encabezado por las luer- 
zas que habían sido desplazadas del poder; el relormista modemizante, encabezado por el conjunto de fuerzas que sostienen a la junta civicomilitar de gobierno; y el revolucionario, que dirigen principalmente los grupos político-militares, que se agruparán un año después en el FMLN. El proyecto relormista deja de tener vigencia muy rápidamente. Hacia el 9 de enero de 1980, con el pacto PDC-fuerza armada, las relormas iniciadas dan un vuelco para apoyar el proyecto contrainsurgente, polarizándose la siluación durante 1980. En el sector democrático-revolucionario se ubica la alianza FDR-FMLN (el FDR se crea en abril v el FMLN en oclubre); y en el conservador del PDC, las fuerzas armadas y los seclores económicos y polílicos oligárquicos. La guerra civil estalla el 10 de enero de 1981.

EI PDC encabeza la junta de gobierno hasta mediados de 1982. La instalación de la Asamblea Constituyente, producto de las elecciones de marzo de 1982, ${ }^{38}$ promueve la creación de un "Gobierno de Unidad Nacional", que institucionaliza un conjunlo de nuevas reglas del juego. Este gobierno lo encabeza Alvaro Magaña. Magańa es nombrado a raíz del Paclo de Apaneca, del 3 de agosio de 1982. El Paclo de Apaneca fue promovido por la fuerza armada y la embajada de Estados Unidos para lograr el equilibrio del poder entre el PDC y los sectores ubicados a su derecha, principalmente ARENA y el PCN. En la instalación de la constituyente es notorio la presencia de la derecha, al presidir la Asamblea Roberto D'Aubuisson, máximo dirigente de ARENA. La nueva Constilución termina de redactarse en diciembre de 1983. En marzo de 1984 se producen elecciones presidenciales y legislativas: el PDC obtiene el $43.41 \%$ de la volación, ARENA el $29.77 \%$ y el PCN el $19.31 \%$ (el reslo corresponde a cinco pequeños partidos, que juntos no logran el $6 \%$ de los volos). En la segunda vuella elecloral de mayo Duarle logra la mayoria absoluta, $y$ toma posesión el primero de junio de 1984,39

Duarle busca imprimir una nueva imagen a su gobierno. Su discurso se basa en que es la "lercera fuerza" que no comparte proyeclos "extremistas", ni de "ultraizquierda" ni de "ullraderecha" (la primera seria la alianza FDR-FMLN y la segunda seria ARENA). Debido a la guerra civil. la crisis económica y otros faclores como el terremoto del 10 de octubre de 1986. se da la reorganización y consolidación de la derecha política, encabezada por ARENA, que acusa de ineficaz a Duarte en el esfuerzo contrainsurgente. dirige un nuevo discurso polílico basado en un aqudo nacionalismo, criticando la implementación de la guerra de baja inlensidad por su fracaso promoviendo lácticas militares acordes a la noción de "guerra total". 41 Por estas razones, a las cuales se agregan elemenlos como la enlermedad de Duarte y acusaciones de corrupción, ARENA logra un triunlo arrollador sobre el PDC en las elecciones legislativas y municipales de marzo de 1988: obtiene 30 diputados contra 22 del PDC y 178 alcandías contra 79 del PDC. 
En las elecciones de marzo de 1988 se pone en evidencia: primero, el completo fracaso del intento de consirucción de un sistema politico legítimo, que encabezara el PDC. Entre las principales razones se encuentra el carácter excluyente de las fuerzas políticas ubicadas a la izquierda del PDC. por lo que el juego electoral se convierte en una dispula por el poder, donde los protagonistas no enfrentan proyectos políticos sustancialmente diferenles. Segundo, que las fuerzas políticas progresistas $\mathrm{y}$ el movimiento popular no participan de la política legal existente. Eslo es válido tanto para el conjunto de movimientos politicos, sindicales, campesinos, entre otros, que no plantean ni comparten la lucha armada, como para el movimiento revolucionario que encabeza el FMLN. Tercero. que el conjunto de planteamientos que sostienen la necesidad de una solución política negociada al conflicto (como el impulsado por la "Convergencia Democrática"), ${ }^{42}$ es dilicil en el contexto político actual, que esta idea pueda compartirse en el seno de la actual élite política ${ }_{1}$ por la incidencia de "los actores reales del poder en el Salvador": el alto mando de la fuerza armada el gobierno estadounidense y la olioarquía.

\section{6) Reflexión final}

El hecho de que por otra vez conseculiva los sectores representantes de la extrema derecha en EI Salvador tenga acceso a las principales instituciones del Estado y sistema político (el alto mando de la fuerzas armadas, la Asamblea Nacional y la presidencia - si llegan al poder en las elecciones presidenciales de marzo y mayo de 1989) demuestra la hipótesis de que la guerra, expresión militar de una completa polaridad política, se corresponde a la política de manera real. El espacio de acción de la política legal: las ciudades y el sur-occidente, territorios bajo el control mililar del gobierno, son las áreas donde se reproduce el poder político-instilucional (a través de las elecciones). Los fracasados intentos por consiluir un sistema político "democrático" a través del PDC. son la expresión de la permanente crisis de hegemonia que se vive en el pais.

Durante 1987, producto de la firma de los acuerdos de Esquipulas II, se abrió la expectaliva de que la tendencia a la prolongación de la guerra pudiera ser sustituida por un pacio político donde participaran todos los sectores del pais, La implementación formal de los acuerdos por parte del gobierno, donde nunca existió voluntad real de negociación, por confiar en los resultados de las estrategias militares implementadas contra el FMLN, hace que se continúe privilegiando a los elementos militares y gue se tome en cuenta a los polílicos sólo como una expresión subordinada a los primeros. 
Por eso, en el pais existen cualro opciones en el corto y mediano plazo: 1) la victoria de las fuerzas gubernamentales contra el FMLN; 2) la victoria de las tuerzas gubemamentales sobre el FMLN, apoyadas por destacamentos de las fuerzas armadas de Estados Unidos; 3) la victoria de las fuerzas insurgentes del FMLN sobre la fuerza armada; y 4) la negociación política, que debe incluir al conjunto de los seclores sociales y politicos del país. De no darse alguna de estas variables como allernativa (reaccionaria, revolucionaria o reformista), la prolongación de la actual guerra civil es la realidad que sutrirá el pueblo salvadoreño en los años por venir.

\section{NOTAS}

1. Comparando 1970 con 1980 , se agudiza la distribución del ingreso en El Salvador, en detrimento de los sectores de más bajos recursos; en el primer año el $20 \%$ más pobre de la población capta el $3.7 \%$ del ingreso, mientras que el $20 \%$ más rico de la población concentra el $50.8 \%$ del ingreso. En 1980 , el $20 \%$ más pobre capta el $2 \%$ del ingreso y el $20 \%$ más rico el $66 \%$. CEPAL, Notes sobre la evoluclón del desarrollo coclal del letmo centroamericano hasta 1980, México, 1983, p. 15.

2. Anderson, Thomas EI Salvador 1932. Los sucesos politicos, EDUCA, San José, 1976.

3. Cabarrús, Carlos Génesle de una revoluclón. And́llsle del surglmlento y desarrollo de la organizaclón capealna en El Salvador, Casa Chata, Méxió, 1983.

4. Son tres relormas las que se impulsan: la Relorma Agraria, la Nacionalización de la Banca y la Nacionalización del Comercio Exterior. La primera junta civico-militar se disuelve hacia el 9 de enero de 1980.

5. Bacevich, A. J, James Hallums, Richard White y Thomas Young "American Military Policy and the Lessons Learned Irom EI Salvador", The John F. Kennedy School of Gobemment, March 1988.

6. Constituctón Polítlea de El Salvador, Publicada en el Diario Oticial, No. 281, 16 de diciembre de 1983.

7. Estatulos det Partldo "Allanza Republlcana Naclonallsta" (ARENA), San Salvador, 1981.

8. La economla comienza a tener leves reactivaciones, por lograr estabilizar flujos regulares de capilal, provenientes de los salvadoreños residentes en Estados Unidos y de la ayuda financiera del gobiemo de ese pals.

9. Por pobreza absoluta se entiende a aquellas lamilias cuyo ingreso no alcanza a cubrir el costo de la canasta básica de alimentos. Ver de Carlos Briones "Realidad y perspectivas de la pobreza en El Salvador, Boletín de clenclas eonómlcas y socialea, Año $X$ No. 6, Universidad Centroamericana, San Salvador, noviembre-diciembre de 1987, págs. 430 y 435.

10. La baja en la lasa de analfabetismo no se debe a un mejoramieno de los niveles educativos, sino a que se he expulsado por la guerra principalmente a población rural, donde se ubica la más alta tasa (en 1985 es de $70 \%$, el anallabetismo rural). Ver Jaime Miranda "Educación e infancia en El Salvador". Boletín de clenclas económlcas y soctales, op. cit., p. 507.

11. Gallardo, Ma. Eugenia y José R. López Centroamérlca. La crlsis en cifras, IICAFLACSO, San José, 1986, p. 197.

12. Hatfiel, Mark, Jim Leach y Goorge Miller Bankrolling Fallure: Unlled Slales Polley In EI Salvador and the Urgent Need For Relorm. A Report to the Arms Control and Foreign Policy Caucus, Wa., november, 1987, p. 20. 
13. Gallardo, Ma. Eugenia y José R. López op. clt., p. 56.

14. Idem., p. 189.

15. Citras oficiales, tomadas de Ricardo Cordova La militarizaclón de Centroemérica (1980-1985), Documento del Proyecto de Investigación de la Universidad de las Naciones Unidas "Violencia, derechos humanos y sobrevivencia cultural en América Labina", Mexico, diciembre de 1985, p. 10.

16. Grupo Ad Hoc del MIPLAN y CONADES "La población desplazada 1980-1987" Presenela año 1, No. 1, CENITEC, San Salvador, abril-junio de 1988, p. 126.

17. Idem, p. 127.

18. Idem, P. 129.

19. Torres-Aivas, Edelberto "Inlorme sobre el estado de la migración en Centroamérica", en La migración centroamericana y la slluación de los salvadoreńos desplazsdos y refugladoe, CINAS. Cuademo de Trabajo No. 7, México, agosto de 1986, p. 9.

20. General Accounting Office. United States Central American Relugees: Reglonal Conditlone and Proepects and Potentlal Impact on the United States, Wa. GAO/NSIAD-84106, 1984, pág. 6.

21. Montes, Segundo Salvadorofos reluglados en los Estadoe Unldos UCA Editores, San Salvador, 1987, p. 34.

22. Esto lo hemos estudiado en detalle en La leorla milltar y la guerre clvll en EI Salvador. UCA Editores, San Salvador, 1988.

23. Desde el inicio de la administración Reagan es Iratado insistentemente de demostrar el apoyo de los gobiemos socialistas al FMLN, principalmente de Cuba, utitizando el recurso de que Nicaragua es el terrilorio trampolin. Ver United States Department of State Communlet Interference In El Salvador, Special Report No. B0, Wa. D.C., Feb. 23, 1981.

24. Pacto Democracia Cristiana-Fuerza Armada el 9 de enero de 1980. La Fuerza Armade al pueblo salvadorerio", Anexo 15 del libro de Mariano Castro Morán Función politlea del eferelto ealvadorefio en ol presente siglo. UCA Editores, San Salvador, 1984, pp. 426-419.

25. Hedar, Arnon The United States and El Sslvador: Pollical and Milltary Involvenment, U.S. -El Salvador Research and Information Center, Berkeley, Ca., 1981, p. 6.

26. Ver:

- Hattield, Mark, Jim Leach y George Miller Bankrolling Fallure: Unlted States Pollcy In El Selvador and the Urgent Need for Felorm, op. cit.

- Hatfield, Mark, Jim Leach y George Miller U.S. Ald to El Salvador: An Evaluation of the Past. A proposal for the Future, Wa. D.C., Arms Control and Foreign Policy Caucus, February, 1985.

27. Gallardo, Ma. Eugenia y José R. López op. clt., p. 47.

28. El Año Fiscal (Fiseal Year) en Estados Unidos se inicia en octubre del año inmediato anterior. Ver los dos documentos citados en la Nola 26

29. Hatfield, Mark, Jim Leach y George Miller U.S. Ald to EI Salvador: An Evaluatlon of the Past. A Proposal for the Future, op. cit. Se menciona en éste reporte, que del total de la asistencia entregada de 1981 a $1985,44.1 \%$ tue ayuda indirecta relacionada con la guerra, $30 \%$ ayuda directa relacionada con la guerra, $15.4 \%$ ayuda para relormas y desarrollo y el $10.5 \%$ ayuda en alimentos (para la población desplazada. principalmente).

30. Becevich, A. J., James Hallums, Richard White y Thomas Young American Military Policy and the Lessons Learned from El Salvador", op. cit., p. 11.

31. United States Departmen of State E Salvador: Revolullon or Reform ?. Current Policy No. 546. Wa. February 1984, p. 7.

32. Bermúdez, Lilia Guerra de baja Inteneldad. Reagan contra Centraomérlca, Siglo XXXI, México, 1987, pp. 142-160.

33. Sánchez, Irene "La nueva estrategia contrainsurgente en El Salvador, Estudios La- 
tinoamerkanos, No. 2, CELA, FCPyS, UNAM, México, enero-junio de 1987.

34. EI FMLN se funda el 10 de octubre de 1980, y está integrado por cinco organizaciones que postulan la lucha armada como lorma de acceder al poder en El Salvador: el Ejército Revolucionario del Pueblo, las Fuerzas Populares de Liberación Farabundo Martl, la Resistencia Nacional, el Partido Revolucionario de los Trabajadores Centroamericanos y el Partido Comunista de El Salvador.

35. Benltez Manaut, Raúl "La guerra lotal en El Salvador, Electos del conflicto bélico en la economia y la población". Revista Mexicana de Clenclas Politicas y Soclales, No. 132 FCPyS, UNAM, México, abril-junio de 1988, pp. 54 y 55.

36. El Salvador. Proceso. Informallvo Semanal. Centro Universitario de Documentación e Información, Universidad Centroamericana, Año 7, No. 269, San Salvador. diciembre de 1986, p. 13.

37. El Selvador. Proceso. Informativo Semanal. Centro Universitario de Documentación e Información, Universidad Centroamericana, Año 8, No. 317, San Salvador, diciembre de 1987, p. 15.

38. En la Asamblea Constituyente el PDC tiene 24 diputados, ARENA 19 y el PCN 14 de un tobal de 60.

39. Córdova, Picardo "El proceso politico salvadoreño (1979-1984)", en El Salvador: Proceso Politico y Guerra (1979-1986), CINAS, Cuaderno de Divulgación No. 4, San Salvador, noviembre de 1987, p. 17.

40. Estatutos del Partido "Allanza Republlcana Naclonallstas" (ARENA), op. cit.

41. Al respecto. ARENA alima que se debe impulsar una estrategia contrainsurgente basada en la "guerra tolal", similar a la implementada en Guatemala, donde parte importante de la actividad militar recayó en la población civil (mediante el genocidio).

42. La Convergencia Democrática es creada a principios de noviembre de 1987. Está formada por los dos partidos politicos miembros del FDR, el Movimiento Nacional Pevolucionerio (MNP) y el Movimiento Popular Social Cristiano (MPSC), y el Partido Social Demberata (PSD). Ver "Los Partidos Politicos MNP, MPSC y PSD han dado pie a un proceso de Convergencia Democrática", Estudloe Centroamericanos, No. 469470. San Salvador, noviembre-diciembre de 1987, pp. 935-938. 